\title{
Study on the correlation between physical activity level and quality of life 1 year after stroke
}

\author{
Suqin Sheng ${ }^{1 \#}$, Liliang Chen ${ }^{2 \#}$, Zeng Chen ${ }^{1}$, Ji Zeng $^{2}$, Jingjing Zheng ${ }^{1}$, Zheng Bei ${ }^{3}$ \\ ${ }^{1}$ Department of Rehabilitation, Cadre Sanatorium of Hainan and Geriatric Hospital of Hainan, Haikou, China; ${ }^{2}$ Department of Rehabilitation, \\ Central South University Xiangya School of Medicine Affiliated Haikou Hospital, Haikou, China; ${ }^{3}$ Department of Spinal Cord Injury Rehabilitation, \\ Cadre Sanatorium of Hainan and Geriatric Hospital of Hainan, Haikou, China \\ Contributions: (I) Conception and design: S Sheng, L Chen, Z Bei; (II) Administrative support: Z Chen, J Zeng; (III) Provision of study materials or \\ patients: J Zheng; (IV) Collection and assembly of data: All authors; (V) Data analysis and interpretation: S Sheng, L Chen, Z Bei; (VI) Manuscript \\ writing: All authors; (VII) Final approval of manuscript: All authors. \\ \#These authors contributed equally to this work. \\ Correspondence to: Zheng Bei. Department of Spinal Cord Injury Rehabilitation, Cadre Sanatorium of Hainan \& Geriatric Hospital of Hainan (CSH), \\ 15 Xinqiao Road, Fucheng Town, Qiongshan District, Haikou 571100, China. Email: beizheng8681@163.com.
}

Background This study sought to assess the correlation between the level of physical activity (PA) and quality on life 1 year after stroke.

Methods: The subjects for this study comprised 122 patients who had their first stroke and were admitted to our hospital from June 2019 to December 2020. The self-rating Stroke Impact Scale (SIS) was used to evaluate the impact of stroke on cognition. The SIS uses a total of 59 items across 8 different dimensions (i.e., strength, memory, emotion, communication, activities of daily living, activity ability, hand function, and participation ability) to assess patients' perceptions of the impact of stroke. All data were expressed as mean \pm standard deviation, median (quartile), and the number of cases (percentage). The $t$-test was used to compare differences between groups, and the chi-square test was used to evaluate percentage differences. A multivariate logistic regression model was used to analyze the correlation between the PA level and the scores of different SIS dimensions.

Results: The average age of subjects in the active group [61.8 (10.7) years] was significantly lower than that of subjects in the inactive group [69.3 (9.3) years] $(\mathrm{P}=0.003)$; however, there was no significant difference in other baseline data. The likelihood of strength recovery, emotional recovery, mobility recovery, participation ability recovery, and stroke recovery was 3.48 [odds ratio $(\mathrm{OR})=4.48,95 \%$ confidence interval (CI): 2.18 5.76], 1.53 (OR =2.53, 95\% CI: 1.92-3.91), 2.32 (OR =3.32, 95\% CI: 2.79-5.81), 4.77 (OR =5.77, 95\% CI: 3.19-6.92), and 7.57 ( $\mathrm{OR}=8.57,95 \% \mathrm{CI}$ : 5.39-9.82) times higher in the active group than the inactive group, respectively $(\mathrm{P}<0.05$ for all).

Conclusions: A significant positive correlation was found between the PA of stroke patients and the recovery of quality of life 1 year after stroke; thus, stroke patients are encouraged to increase their PA.

Keywords! Physical activity (PA); stroke; quality of life

Submitted Apr 02, 2021. Accepted for publication May 08, 2021.

doi: 10.21037/apm-21-962

View this article at: http://dx.doi.org/10.21037/apm-21-962 


\section{Introduction}

Physical activity (PA) has many benefits to human health, such as reducing the risk of heart disease, cancer, and stroke (1). The level of adequate PA for adults is defined as at least 150 minutes of moderate-intensity aerobic exercise per week combined with regular strength training (2). Despite the promotion of PA all over the world (1), insufficient $\mathrm{PA}$ is still one of the 5 most preventable risk factors for stroke. Additionally, studies have shown that the PA level of patients after stroke is significantly lower than that of healthy controls (3). The symptoms of a stroke are diverse, and include reduced motor function, coordination, and sensory and cognitive functions (4). Studies have shown that task training in stroke rehabilitation can improve muscle strength, walking ability, and cardiopulmonary function (5-8). Studies have also found that high levels of PA alone can improve functional skills, such as walking ability, balance and physical fitness after stroke (9). However, research has also shown that physical function alone cannot explain the level of PA after stroke $(10,11)$. Detecting clinical outcomes after stroke is a complex process. According to the International Classification of Function, Disability, and Health, a multidimensional examination of health is essential (12). Multidimensional measurement tools, such as the Stroke Impact Scale (SIS) $(13,14)$, can check various functions, activity levels, and participation levels. Studies have also shown that personal perceptions of health are important (15), and support the use of self-assessment scales, such as the SIS.

An increase in PA has many physical and psychological benefits $(16,17)$. However, studies have shown that stroke patients display greater physical exertion (18), and higher PA may lead to increased fatigue and ultimately aggravate the impact of stroke on patients' lives. Thus, it is important to understand the relationship between the degree of PA and the impact of stroke on life, as it may affect the formulation and selection of long-term recovery programs after stroke. The present study sought to evaluate the correlation between the level of PA and quality of life 1 year after stroke. We present the following article in accordance with the STROBE reporting checklist (available at http:// dx.doi.org/10.21037/apm-21-962).

\section{Methods}

\section{Research subjects}

One hundred and twenty-two patients, who attended our hospital suffering from their first stroke from June 2019 to December 2020, were included in the study. To be eligible to participate in the study, patients had to meet the following inclusion criteria: (I) have received a first diagnosis of stroke; (II) show a functional decline of arms and hands after stroke, according to the Action Reach Arm Test (via a score $\leq 57$ points); (III) have been admitted to a stroke center within 3 days of the stroke occurring; (IV) be aged $\geq 18$ years; and (V) have completed the Saltin Grimby 6-Level Physical Activity Scale (SGPALS) and the SIS assessment 1 year after stroke. Conversely, patients were excluded from the study if they met the following exclusion criterion: (I) had upper limb dysfunction that had already existed before the stroke because of trauma or other conditions. All procedures performed in this study involving human participants were in accordance with the Declaration of Helsinki (as revised in 2013). The study was approved by the Research Ethics Committee of the Cadre Sanatorium of Hainan and the Geriatric Hospital of Hainan (No.: 2018062) and informed consent was taken from all the patients.

\section{Evaluation method}

The SIS is a self-rating scale that is used to assess the impact of stroke on cognition (14). The SIS uses a total of 59 items across 8 different dimensions (i.e., strength, memory, emotion, communication, activities of daily living, activity ability, hand function, and participation ability) to assess patients' perceptions of the impact of stroke. Each item is scored (from 1-5 points), and a total score is aggregated. The SIS also includes a final question concerning overall stroke recovery (SR) with a score of $0-100$. In this study, variable 1 (strength), variable 3 (emotion), variable 6 (mobility), variable 8 (participation), and SR were selected for analysis, as previous research has shown that these variables may be closely related to PA (18). At 1 year after stroke, the SGPALS was used to measure the PA level of the subjects in the past 6 months, and a 6-level ordered scale for PA was used for the self-assessment. Based on the PA level at 1 year, the study population was divided into two groups: an inactive group (equivalent to SGPALS 1-2) and an active group (equivalent to SGPALS 3-6) (19).

\section{Statistical methods}

All data are expressed as mean \pm standard deviation, median (quartile), and the number of cases (percentage). A $t$-test 
Table 1 Baseline data of patients with different levels of physical activity

\begin{tabular}{lccc}
\hline Variables & $\begin{array}{c}\text { Active group } \\
(\mathrm{n}=62)\end{array}$ & $\begin{array}{l}\text { Inactive group } \\
(\mathrm{n}=60)\end{array}$ & $\mathrm{P}$ value \\
\hline Age (year) & $61.8(10.7)$ & $69.3(9.3)$ & 0.003 \\
Male (n, \%) & $38(61.3)$ & $35(58.3)$ & 0.78 \\
Cerebral ischemia (n, \%) & $36(58.1)$ & $34(56.7)$ & 0.353 \\
Smoking (n, \%) & $28(45.2)$ & $31(51.7)$ & 0.08 \\
Drinking (n, \%) & $30(48.4)$ & $35(58.3)$ & 0.21 \\
$\begin{array}{l}\text { Cardiovascular diseases } \\
(\mathrm{n}, \%)\end{array}$ & $25(40.3)$ & $27(45)$ & 0.13 \\
\hline
\end{tabular}

was used to compare differences between the groups, and a chi-square test was used to evaluate percentage differences. A multivariate logistic regression model was undertaken to analyze the correlation between the PA level and the scores of different SIS dimensions. SAS software (version 9.4) was used, and a $\mathrm{P}<0.05$ was considered statistically significant.

\section{Results}

\section{Baseline data of subjects}

As stated above, the subjects were divided into an active group ( $n=62)$ and an inactive group $(n=60)$ according to their PA level at 1 year after stroke. The survey found that the average age of subjects in the active group [61.8 (10.7) years] was significantly lower than that of the inactive group [69.3 (9.3) years] $(\mathrm{P}=0.003)$. The active group comprised 38 males $(61.3 \%), 36$ cerebral ischemia patients $(58.1 \%)$, 28 smoking patients (45.2\%), 30 drinking patients (48.4\%), and 25 cardiovascular disease patients (40.3\%). There was no significant difference between the baseline date of the active and inactive groups. (all $\mathrm{P}>0.05$; see Table 1 ).

\section{Comparison of Stroke Impact Scale dimensions of subjects with different $\mathrm{PA}$ levels}

The quality of life of subjects 1 year after stroke was evaluated according to different SIS dimensions. A comparison of the SIS assessments showed $47 v s .38$ cases of normal strength, $53 \mathrm{vs} .47$ cases of normal emotions, 59 vs. 51 cases of normal mobility, 40 vs. 34 cases of normal participants, and $52 v s .49$ cases in which patients returned to normal after stroke for the active and inactive groups, respectively. The number of patients in the active group
Table 2 Comparison of Stroke Impact Scale dimensions of subjects with different physical activity levels

\begin{tabular}{lccc}
\hline SIS modules & $\begin{array}{c}\text { Active group } \\
(\mathrm{n}=62)\end{array}$ & $\begin{array}{c}\text { Inactive group } \\
(\mathrm{n}=60)\end{array}$ & P value \\
\hline Strength & 47 & 38 & 0.007 \\
Normal & 15 & 22 & \\
Abnormal & 53 & & \\
Emotion & 9 & 47 & 0.02 \\
Normal & & 13 & \\
Abnormal & 59 & 51 & 0.001 \\
Mobility & 3 & 9 & \\
Normal & & & \\
Abnormal & & 34 & 0.003 \\
Participation & 40 & 26 & \\
Normal & 22 & & \\
Abnormal & 52 & 49 & \\
Stroke recovery & & 21 & \\
Normal & & & \\
Abnormal & 50 & & \\
\hline
\end{tabular}

SIS, Stroke Impact Scale.

whose SIS dimensions returned to normal were significantly higher than the number of those in the inactive group $(\mathrm{P}<0.05$ for all; see Table 2$)$.

\section{The correlation between PA (active group vs. inactive group) and quality of life}

A logistic regression analysis of the correlation between PA (active group $v s$. inactive group) and quality of life found that the likelihood of strength recovery, emotional recovery, mobility recovery, participation ability recovery and SR was 3.48 [odds ratio $(\mathrm{OR})=4.48,95 \%$ confidence interval (CI): 2.18-5.76], 1.53 (OR =2.53, 95\% CI: 1.92-3.91), 2.32 $(\mathrm{OR}=3.32,95 \%$ CI: 2.79-5.81), 4.77 (OR $=5.77,95 \%$ CI: 3.19-6.92), and 7.57 (OR =8.57, 95\% CI: 5.39-9.82) times higher in the active group than the inactive group, respectively $(\mathrm{P}<0.05$ for all; see Table 3$)$.

\section{Stratified analysis of the correlation between PA (active group vs. inactive group) and quality of life}

A further stratified analysis of the correlation between PA 
Table 3 The correlation between physical activity (active group vs. inactive group) and quality of life

\begin{tabular}{lccc}
\hline Variables & OR & $95 \% \mathrm{Cl}$ & P value \\
\hline Strength & 4.48 & $2.18-5.76$ & $<0.0001$ \\
Emotion & 2.53 & $1.92-3.91$ & $<0.0001$ \\
Mobility & 3.32 & $2.79-5.81$ & $<0.0001$ \\
Participation & 5.77 & $3.19-6.92$ & $<0.0001$ \\
Stroke recovery & 8.57 & $5.39-9.82$ & $<0.0001$
\end{tabular}

OR, odds ratio; $\mathrm{Cl}$, confidence interval.

(active group $v s$. inactive group) and quality of life based on gender and age showed that in most subgroups, patients in the active group were more likely to achieve restored quality of life than patients in the inactive group $(\mathrm{P}<0.05)$. However, there were no statistically significant differences in the recovery status of the active group and the inactive group for the subgroup of patients aged $\geq 60$ in relation to strength recovery, the subgroup of male patients in relation to emotional recovery, the subgroup of patients aged $\geq 60$ in relation to mobility recovery, and the subgroup of patients aged $\geq 60$ in relation to SR (all $\mathrm{P}>0.05$; see Table 4).

\section{Discussion}

This study found that PA was significantly positively correlated with the recovery of patients' quality of life (as assessed by the SIS dimensions) 1 year after stroke. The results of the present study indicate that helping stroke patients become PA may have a positive impact on their lives, as PA is related to increased long-term participation ability after stroke.

A recent study confirmed that SIS-8 (i.e., a sense of participation) is sensitive to changes over time, and found that almost $50 \%$ of the study population showed a significant positive or negative change between 3 months and 1 year after stroke (20). Guidetti et al. found that SR (as assessed by the SIS) at 1 year after stroke was significantly better than SR at 3 months after stroke (21), and was independent of changes in age, gender, and other dimensions of the SIS. In this study, SR was independent of age, gender, stroke type, living habits, and past heart disease history. However, higher levels of PA were associated with better SR.

The recovery of the 5 dimensions of SIS investigated in this study confirmed that there is a correlation between
Table 4 Stratified analysis of the correlation between physical activity (active group vs. inactive group) and quality of life

\begin{tabular}{|c|c|c|c|}
\hline Variables & OR & $95 \% \mathrm{Cl}$ & $\mathrm{P}$ value \\
\hline \multicolumn{4}{|l|}{ Strength } \\
\hline$<60$ years old & 4.51 & $2.29-6.03$ & $<0.0001$ \\
\hline$\geq 60$ years old & 1.17 & $0.92-3.38$ & 0.23 \\
\hline Male & 4.23 & $3.14-5.81$ & $<0.0001$ \\
\hline Female & 4.57 & $2.13-5.49$ & $<0.0001$ \\
\hline \multicolumn{4}{|l|}{ Emotion } \\
\hline$<60$ years old & 2.32 & $1.04-4.02$ & $<0.0001$ \\
\hline$\geq 60$ years old & 2.61 & $1.87-4.18$ & $<0.0001$ \\
\hline Male & 1.12 & $0.91-4.03$ & 0.06 \\
\hline Female & 3.07 & $1.89-3.87$ & $<0.0001$ \\
\hline \multicolumn{4}{|l|}{ Mobility } \\
\hline$<60$ years old & 3.07 & $2.69-5.92$ & $<0.0001$ \\
\hline$\geq 60$ years old & 1.44 & $0.78-5.11$ & 0.13 \\
\hline Male & 3.15 & $2.63-4.99$ & $<0.0001$ \\
\hline Female & 3.42 & $2.71-5.82$ & $<0.0001$ \\
\hline \multicolumn{4}{|l|}{ Participation } \\
\hline$<60$ years old & 5.79 & $3.21-6.03$ & $<0.0001$ \\
\hline$\geq 60$ years old & 5.17 & $3.89-7.02$ & $<0.0001$ \\
\hline Male & 5.21 & $4.09-6.19$ & $<0.0001$ \\
\hline Female & 5.83 & $5.18-7.32$ & $<0.0001$ \\
\hline \multicolumn{4}{|l|}{ Stroke recovery } \\
\hline$<60$ years old & 8.77 & $6.02-9.98$ & $<0.0001$ \\
\hline$\geq 60$ years old & 1.24 & $0.91-6.22$ & 0.18 \\
\hline Male & 7.32 & $6.91-9.91$ & $<0.0001$ \\
\hline Female & 8.83 & $7.09-9.28$ & $<0.0001$ \\
\hline
\end{tabular}

OR, odds ratio; $\mathrm{Cl}$, confidence interval.

higher PA levels and better recovery of quality of life in patients 1 year after stroke. As mentioned above, a previous study found that compared to healthy people, stroke patients expend more energy (21). However, the findings of the present study to not support this hypothesis. This study found that the higher the level of PA, the greater the energy expenditure and the more increased the fatigue, but the greater the positive effect on quality of life.

Studies have shown that multidisciplinary rehabilitation after stroke is necessary to minimize long-term symptoms 
and restore social function through early participation in teamwork (22). Additionally, to improve the long-term PA level after stroke, individualized interventions are beneficial (23). The stroke rehabilitation process is very complicated. The findings of this study emphasize the importance of helping stroke survivors achieve sufficient PA levels.

It should be noted that this study had a number of limitations. First, other variables may affect the results, such as cultural and religious differences. Second, the sample size included in this study was limited, and thus more research needs to be conducted to support the conclusions. Finally, the population included in this study was middle-aged and elderly. However, the low PA level of this population hindered a full analysis of the correlation between higher PA levels and the recovery of quality of life after stroke.

In summary, this study found a significant positive correlation between the PA of stroke patients and the recovery of quality of life 1 year after stroke. Stroke patients should be encouraged to increase their PA to promote the improvement of the quality of life in terms of strength, emotion, mobility, participation, and SR.

\section{Acknowledgments}

Funding: None.

\section{Footnote}

Reporting Checklist: The authors have completed the STROBE reporting checklist. Available at http://dx.doi. org/10.21037/apm-21-962

Data Sharing Statement: Available at http://dx.doi. org/10.21037/apm-21-962

Conflicts of Interest: All authors have completed the ICMJE uniform disclosure form (available at http://dx.doi. org/10.21037/apm-21-962). The authors have no conflicts of interest to declare.

Ethical Statement: The authors are accountable for all aspects of the work in ensuring that questions related to the accuracy or integrity of any part of the work are appropriately investigated and resolved. All procedures performed in this study involving human participants were in accordance with the Declaration of Helsinki (as revised in 2013). The study was approved by the Research Ethics
Committee of the Cadre Sanatorium of Hainan and the Geriatric Hospital of Hainan (No.: 2018062) and informed consent was taken from all the patients.

Open Access Statement: This is an Open Access article distributed in accordance with the Creative Commons Attribution-NonCommercial-NoDerivs 4.0 International License (CC BY-NC-ND 4.0), which permits the noncommercial replication and distribution of the article with the strict proviso that no changes or edits are made and the original work is properly cited (including links to both the formal publication through the relevant DOI and the license). See: https://creativecommons.org/licenses/by-nc-nd/4.0/.

\section{References}

1. Australian Institute of Health and Welfare. Australia's health 2018. Australia's Health Series No. 16, 2018.

2. Zhang $\mathrm{Y}$, Chapman AM, Plested $M$, et al. The incidence, prevalence, and mortality of stroke in France, Germany, Italy, Spain, the UK, and the US: a literature review. Stroke Res Treat 2012;2012:436125.

3. The economic impact of stroke in Australia. Deloitte Access Economics commissioned by the Stroke Foundation. In: 2013

4. O'Donnell MJ, Chin SL, Rangarajan S, et al. Global and regional effects of potentially modifiable risk factors associated with acute stroke in 32 countries (INTERSTROKE): a case-control study. Lancet 2016;388:761-75.

5. Warburton DE, Nicol CW, Bredin SS. Health benefits of physical activity: the evidence. CMAJ 2006;174:801-9.

6. Warburton DER, Bredin SSD. Health benefits of physical activity: a systematic review of current systematic reviews. Curr Opin Cardiol 2017;32:541-56

7. Penedo FJ, Dahn JR. Exercise and well-being: a review of mental and physical health benefits associated with physical activity. Curr Opin Psychiatry 2005;18:189-93.

8. Kramer AF, Erickson KI. Effects of physical activity on cognition, well-being, and brain: human interventions. Alzheimers Dement 2007;3:S45-51.

9. Erickson KI, Hillman CH, Kramer AF. Physical activity, brain, and cognition. Current Opinion in Behavioural Sciences 2015;4:27-33.

10. Cotman CW, Berchtold NC. Exercise: a behavioral intervention to enhance brain health and plasticity. Trends Neurosci 2002;25:295-301.

11. Tolppanen AM, Solomon A, Kulmala J, et al. Leisure-time 
physical activity from mid- to late life, body mass index, and risk of dementia. Alzheimers Dement 2015;11:434443.e6.

12. Podewils LJ, Guallar E, Kuller LH, et al. Physical activity, APOE genotype, and dementia risk: findings from the Cardiovascular Health Cognition Study. Am J Epidemiol 2005;161:639-51.

13. Reinholdsson M, Palstam A, Sunnerhagen KS. Prestroke physical activity could influence acute stroke severity (part of PAPSIGOT). Neurology 2018;91:e1461-7.

14. Ploughman M, Austin MW, Glynn L, et al. The effects of poststroke aerobic exercise on neuroplasticity: a systematic review of animal and clinical studies. Transl Stroke Res 2015;6:13-28.

15. Saunders DH, Sanderson M, Hayes S, et al. Physical fitness training for stroke patients. Cochrane Database Syst Rev 2016;(3):CD003316.

16. Caspersen CJ, Powell KE, Christenson GM. Physical activity, exercise, and physical fitness: definitions and distinctions for healthrelated research. Public Health Rep 1985;100:126-31.

17. Pate RR. A new definition of youth fitness. Physician

Cite this article as: Sheng S, Chen L, Chen Z, Zeng J, Zheng J, Bei Z. Study on the correlation between physical activity level and quality of life 1 year after stroke. Ann Palliat Med 2021;10(5):5627-5632. doi: 10.21037/apm-21-962
Sportsmed 1983;11:77-83.

18. Lee CD, Folsom AR, Blair SN. Physical activity and stroke risk: a meta-analysis. Stroke 2003;34:2475-81.

19. Brott T, Adams HP Jr, Olinger CP, et al. Measurements of acute cerebral infarction: a clinical examination scale. Stroke 1989;20:864-70.

20. Decourcelle A, Moulin S, Sibon I, et al. Influence of previous physical activity on the outcome of patients treated by thrombolytic therapy for stroke. J Neurol 2015;262:2513-9.

21. Guidetti S, Ytterberg C, Ekstam L, et al. Changes in the impact of stroke between 3 and 12 months post-stroke, assessed with the Stroke Impact Scale. J Rehabil Med 2014;46:963-8.

22. Deplanque D, Masse I, Libersa C, et al. Previous leisuretime physical activity dose dependently decreases ischemic stroke severity. Stroke Res Treat 2012;2012:614925.

23. Krarup LH, Truelsen T, Gluud C, et al. Prestroke physical activity is associated with severity and long-term outcome from first-ever stroke. Neurology 2008;71:1313-8.

(English Language Editor: L. Huleatt) 